\title{
Injustiças vividas e demandas por reconhecimento numa escola pública: expressões de estudantes de ensino médio'1
}

\author{
Alice Miriam Happ Botler² \\ ORCID: 0000-0001-5654-3248
}

\section{Resumo}

Este artigo procura examinar a expressão de estudantes de ensino médio relativa às injustiças vividas no cotidiano da escola democrática e às demandas dai decorrentes. Trata-se de recorte de uma pesquisa que teve por objetivo geral analisar as concepções que os sujeitos escolares têm de justiça, o que está associado às situações de conflitos e violências na organização escolar. 0 debate teórico trata de conceitos como justiça plural, práticas escolares e identidade. 0 estudo de caso via grupos focais com estudantes do ensino médio de uma escola pública de Recife gerou debate entre os sujeitos, cujas manifestações indicam a forte presença de discriminação, especialmente do ponto de vista religioso e racial, como aspecto que desperta o sentimento de injustiça em parte dos escolares. Conclui-se que esse sentimento os leva a apresentar resistências, assim como potencializa sua identificação com o universo escolar específico. Os estudantes demandam o reconhecimento de suas identidades religiosas, étnicas e raciais, que são silenciadas no dia a dia na escola. A instituição, por sua vez, falha ao evitar o debate a respeito de temas tão presentes ali e perde oportunidades de mobilizar estudantes na perspectiva de criar uma maior aproximação com a escola.

\section{Palavras-chave}

Escola justa - Justiça plural - Injustiça - Reconhecimento.

1- Pesquisa financiada com apoio do Edital Universal CNPq - Processo n 444372/2014-8 2.

2- Universidade Federal de Pernambuco, Recife, PE, Brasil. Contato: alicebotler@gmail.com 


\section{Injustices experienced and demands for recognition in a public school: expressions of High School students}

\section{Abstract}

This paper seeks to examine the expression of High School students regarding the injustices experienced in the daily life of the democratic school and its resulting demands. This is part of a research that aimed to analyze the conceptions that school subjects have of justice, which is associated with situations of conflict and violence in the school organization. The theoretical debate deals with concepts such as plural justice and school practices. The case study via focus groups with High School students from a public school in the city of Recife, Pernambuco, Brazil, generated debate among the subjects, whose manifestations indicate the strong presence of discrimination, especially from a religious and racial point of view, as aspects that awaken the schoolchildren's feeling of injustice. It is concluded that this feeling leads them to show resistance, as well as enhances their identification with the specific school universe. Students demand recognition of their religious, ethnic and racial identities, which are silenced in everyday school life. The institution, in turn, fails to avoid the debate about issues that are so present there and loses opportunities to mobilize students with a view to creating a closer relationship with the school.

\section{Keywords}

Fair school - Plural justice - Injustice - Recognition.

\section{Introdução}

Este artigo apresenta parte dos resultados de uma pesquisa que teve por objetivo analisar as concepções que os sujeitos escolares têm de justiça e suas repercussões em termos de relações de poder, violências e indisciplinas na organização escolar. Discutese justiça a partir do ponto de vista das práticas escolares, focalizando uma abordagem micropolítica e microssociológica.

Como referência teórica, utiliza-se a ideia de justiça plural (WALZER, 2003), que tem em vista as tradições e a comunidade reportada, baseada na igualdade complexa. Oferecese, nestes termos, fundamentação crítica à ideia da igualdade liberal, oportunizando um aprofundamento a respeito do conceito tradicional de escola como ambiente tranquilo e harmônico. Tal crítica encontra respaldo também em Rancière (2014, p. 81, grifo do autor), que considera ser necessário "compreender as relações complexas entre democracia, política, república e representação, para compreender o ódio de hoje e encontrar a força subversiva da ideia democrática".

0 recorte aqui apresentado procura examinar a expressão relativa às injustiças vividas no cotidiano da escola democrática e às demandas decorrentes. Assim, o tema 
remete também a autores como Dubet (2004) e Derouet (2010), que tratam da oposição entre justiça e injustiça, tendo como foco os princípios de igualdade, mérito e autonomia, bem como da noção de escola justa. Dubet (2014) questiona ainda o sentimento de discriminação e autonomia em referência à precariedade das condições de cidadania.

Chama-se a atenção para a frequente evidenciação de situações de injustiças ao se tratar do conceito de justiça, aspecto que motivou a proposição do título do artigo.

A discussão teórica é apresentada na primeira parte do texto, em que se discute os antagonismos da escola democrática, bem como a construção do conhecimento vivido e gerado nesse espaço, e auxilia a análise dos dados recolhidos na segunda parte, a partir do estudo de caso em uma escola pública em Recife, em que o trabalho com grupos focais de estudantes do ensino médio permitiu não apenas apreender suas expressões relativas às injustiças vividas, mas também revelou a presença da discriminação de cunho religioso e racial como prática escolar naturalizada.

\section{Justiça e injustiças: antagonismos da escola democrática}

Analisar a (in)justiça do ponto de vista das práticas escolares conduz por um caminho que exige o olhar de quem a experimenta. Para tanto, toma-se Walzer (2003) como importante referência, para quem a noção de justiça é sempre alusiva às tradições e aos valores produzidos e vividos em cada contexto específico e estimula a compreender que os significados sociais de cada indivíduo são comunitários, criados pela sociedade e não por indivíduos isolados.

A noção de justiça distributiva remete à razão comunicativa (HABERMAS, 1989), que ocorre por meio da interação e da linguagem, potencializando a liberdade e a crítica. É, portanto, sustentáculo da justiça, já que por seu intermédio os homens se organizam e buscam consensos livres de coação.

Este é o modo como se desenvolvem as relações sociais afırmativas e suas associações às diversas individualidades, ou "identidades plurais, múltiplas, identidades que se transformam, que não são fixas ou permanentes, que podem, até mesmo, ser contraditórias" (LOUR0, 2010, p. 24), passando a constituir noções de classe, raça, etnia e outros eixos de relações de poder.

Não é o foco e o interesse deste artigo explorar todas as dimensões críticas desse tema já bastante estudado, a exemplo de Brubaker e Cooper (2018). Para esses autores, o termo identidade refere-se tanto a dimensões da vida cotidiana (categoria de prática) quanto a aspectos da vida política (categoria de análise): "A reifıcação é um processo social, não somente uma prática intelectual. Nesse sentido, é central para as políticas de 'etnicidade', 'raça', 'nação' e outras identidades putativas” (BRUBAKER; COOPER, 2018, p. 273).

Os autores analisam as diversas formas de alusão ao termo identidade, seja para se referir às igualdades fundamentais, seja para a rejeição de tal noção, entre outras características que compõem o debate a respeito do tema. Sua crítica incide nos "processos interativos discursivamente mediados pelos quais solidariedades coletivas e autocompreensões são desenvolvidas” (BRUBAKER; COOPER, 2018, p. 289). Em outros termos, esclarecem que "os esforços de construir uma autocompreensão coletiva" não necessariamente conduzem ao correspondente entendimento de "identidade” (p. 290). 
Os autores reforçam ainda a distinção necessária entre a complexidade do uso da expressão identificação enquanto processo socialmente constituído, por um lado, e, por outro, a facilidade do uso de identidade, como categoria ordinária. Essa distinção conceitual permite esclarecer que o uso de categorias como classe, raça e etnia nem sempre comportam a riqueza de sua essência. São, portanto, constituídas socialmente no cotidiano e associadas a relações de poder, que tanto domesticam, mas que também podem servir para esclarecer ideias e organizar as relações sociais como práticas afirmativas e emancipatórias. Nesta perspectiva, é assim, que se configuram as identidades dos sujeitos.

Coelho e Coelho (2015, p. 36) analisam as identidades coletivas a partir das sociabilidades entre adolescentes fora da escola, aludindo a elementos identificadores como a música:
A relação entre estes grupos acabava por conformar uma hierarquia, mantida dentro dos muros escolares, pautada na cor - rock, pop e rap, samba, pagode e tecnobrega não são consumidos de formas estanques, mas são identificados à cor e definem o lugar do sujeito na ordem das coisas, tal como ela lhes parece.

Os autores esclarecem o modo como a discriminação emerge da própria relação social de um grupo autoidentificado. Gomes (2005) compreende que o esclarecimento a respeito de conceitos como racismo, discriminação e preconceito poderia contribuir para a minimização destes problemas na escola, uma vez que potencializaria a identificação de tais práticas para uma atuação mais incisiva. A mesma autora associa a prática de uma justiça cognitiva (o conhecimento de tais conceitos) à ideia de justiça curricular (GOMES, 2019).

Tal processo ocorre mediante disputas por reconhecimento que, conforme Barbosa e Mühl (2016, p. 791), “não se esgotam nessas lutas de identidade”. Esses autores focalizam a erosão dos direitos universais de cidadania, o que poderia ser considerada numa perspectiva de educação emancipatória.

A relação entre educação, cidadania e justiça pode ser analisada à luz de Dubet (2014), que trata do paradoxo fundamental da escola republicana, que prega a laicidade universal, de um lado, e os pertencimentos sociais e culturais privados, por outro, como se a escola não tivesse qualquer relação ou ingerência no exercício da cidadania, propriamente: "A rigidez laica procurava impedir que a democracia entre os alunos reintroduzisse as paixões e as desordens sociais" (DUBET, 2011, p. 292). Em outras palavras, a institucionalidade escolar democrática separa, por princípio, o que os alunos trazem como cultura e expressão, daquilo que importa à escola e faz gerar suas ações: ao mesmo tempo em que universaliza, homogeneíza.

Contraditoriamente, no entanto, a sociedade contemporânea cada vez mais vem abrindo espaço às diversidades, às afirmações de identidades e seus direitos, o que não ocorre livre de conflitos, diante dos quais o grande desafio é tornar a escola um espaço de civilidade, com direitos, deveres e, principalmente, alteridade, noções afetas à cidadania.

Tal dilema se materializa por meio das interações sociais a cada tempo e contexto. Conforme Hall (2006), o processo de identificação não é fixo, mas definido historicamente (não biologicamente), podendo o sujeito assumir identidades diferentes em contextos diferentes. Identidade é, para o autor, relacional e política, ou ainda construída socialmente, como definem Berger e Luckmann (1985). 
Uma das fases decisivas da socialização é a formação do outro generalizado, "que implica a interiorização da sociedade e da realidade objetiva e, ao mesmo tempo, o estabelecimento subjetivo de uma identidade coerente e contínua" (BERGER; LUCKMANN, 1985 , p. 49). Os autores tratam da interação social na vida cotidiana e esclarecem que "na situação face a face o outro é plenamente real. Mesmo assim, apreendo o outro por meio de esquemas tipificadores" (p. 49), nem sempre interiorizados por todos os indivíduos, "porque o conteúdo da socialização é determinado pela distribuição social do conhecimento" (p. 179).

Os conceitos tratados nesta seção auxiliam a perceber que, entre os antagonismos da escola democrática, encontra-se a ideia de torná-la mais justa, implicando na análise de que a própria noção de justiça é compreendida a partir dos significados atribuídos pelos diversos sujeitos e grupos que a constituem. A socialização que se desenvolve e aprofunda no âmbito da escola é repleta de conflitos, que exigem a problematização das diversas identidades em disputa, autorreferenciadas em valores dos próprios grupos que as sustentam, com vistas ao seu compartilhamento e reconhecimento.

\section{A escola como lugar de atuação e produção de conhecimento e valores}

A constante e dinâmica ressignificação das experiências vividas cotidianamente, conforme Fontes (2014), está relacionada ao acúmulo de conhecimentos. Conforme o autor "não devemos, entretanto, esquecer que o conceito de identidade remete tanto ao caráter único daquele que a porta como também ao que compartilha com aqueles com quem interage" (FONTES, 2014, p. 123). 0 acesso ao conhecimento não ocorre apenas por meio da escola, mas nela encontra terreno fértil, o que dá sustentação ao debate substantivo a respeito de princípios, a exemplo da equidade entre sujeitos portadores de diferentes identidades, raças, etnias e credos, já que é lugar inevitável de encontro multicultural. A ausência de conhecimento, então, implica percepção parcial, arbitrária entre sujeitos, também podendo expressar certa visão de hierarquia, desigualdade e, pior, preconceito.

A escola como lugar de produção de conhecimento, valoriza ora mais, ora menos um conjunto de princípios e de visões de mundo partilhados por seus membros. Esses princípios são sempre passiveis de revisão, desde que a interação social oportunize, o que ocorre por meio do diálogo, permitindo tanto apreender a realidade, quanto produzi-la.

Na mesma linha, Ball, Maguire e Braun (2016) focalizam a maneira com que cada escola reage às políticas educacionais e atua, em sua realidade singular, para além dos efeitos diretos dessas políticas. A expressão atuação de políticas é utilizada pelos autores como alusão à elaboração de sentidos por parte dos sujeitos diante dos desafios postos como um "complexo microfísico", em pequena escala, num âmbito particular, o que interessa aprofundar.

No entanto, a literatura mais recente aborda a coibição da liberdade de ensinar, indicando certa reação conservadora aos avanços sociais obtidos em prol das afirmações das identidades das minorias e suas expectativas por direito e justiça, além da classe trabalhadora desde os anos 2000, a exemplo do que é sustentado pelo movimento Escola sem Partido, constituído em 2003, tal como afirma Veiga (2017). A autora, incomodada com o discurso 
da neutralidade política, analisa o processo de inferiorização de parcelas da população presente no projeto civilizador em toda a história brasileira, inclusive via estigmatização no desenvolvimento da educabilidade, que é relacionado à construção do Estado-nação:

A implantação da escolarização para todos somente foi possivel com a monopolização dos saberes pelo Estado, instituição detentora do controle sobre esquecimento e erro histórico, [...] nas práticas violentas e opressoras necessárias para formação de uma cultura comum. (VEIGA, 2017, p. 161).

A homogeneização de uma cultura nacional é, assim, vista como função de “instituições com poder de impor a uniformidade nacional” (VEIGA, 2017, p. 161), a exemplo da escola, que fornece o ensino de uma língua comum com vistas a difundir a opinião pública via meios de comunicação. Relaciona-se, desta forma, a massificação da escolarização ao processo de descolonização, em que a escola é caracterizada como instituição unifıcadora que forma uma nova comunidade política, confıguradajuridicamente por cidadãos livres e iguais. A mesma autora conclui que o projeto civilizador nunca teve efetivamente caráter emancipador, mas, ao contrário, sempre reafirmou uma inferioridade imaginada diante das conquistas sociais que são permanentemente postas em questão por grupos que se sentem ameaçados por elas.

Essa tese é reforçada por Coelho e Coelho (2015, p. 32), que evidenciam que

[...] as sociabilidades observadas incorporam um significativo componente discriminatório, sustentado em preconceitos de cor, raça, gênero e confissão religiosa. Exercidas nas salas de aula, nos corredores, pátios e quadras escolares, elas não constituem objeto de ação educativa.

Este aspecto merece destaque quando se analisa a escola e seus conflitos inerentes. Dayrell (2003) considera que as condições sociais são fundamentais na conformação juvenil, posto ser por meio delas que a experiência se concretiza. Nesse sentido, por outra via, recusa-se a compreensão da condição juvenil como um momento de transição, de preparação para a etapa mais importante da vida, a fase adulta. Em lugar de uma assunção do jovem como um "vir a ser" estritamente etária, Dayrell (2003) propõe entendê-la como uma relação social. E, aqui, talvez resida a novidade do atual momento. Conforme sugere o autor, a socialização juvenil não se dá a partir de um único espaço institucional, como a escola ou a família, mas de instâncias diversas, distintas, eventualmente concorrentes e simultâneas, incidindo com intensidade nas redes sociais virtuais. Disso decorre a sua condição de ator plural, vinculado a um conjunto de instâncias com intensidades variantes no tempo e no espaço.

Essas referências teóricas reforçam a tese de que o diálogo representa uma estratégia de convivência que potencializa cuidar igualmente das diversas formas do sentir, o que permite encontrar certa expressividade iminente, esperando uma pequena oportunidade para se revelar ativa. Chama-se a atenção para a importância do debate em coletivos, com canalização afırmativa dos desejos, ideias e impulsos, possibilitando esclarecer diferentes princípios que levam os sujeitos a terem posições antagônicas, de forma a revelar o que está na raiz dos conflitos e, assim, desvendar os preceitos que geram as ações, ora de caráter individualista, ora social/coletivista. 
A este respeito, Estêvão (2004) esclarece que diferentes espaços inspiram diferentes concepções de justiça, que circulam, inclusive, no espaço escolar: o mundo doméstico, por exemplo, realça os códigos de honra, a tradição do respeito aos mais velhos, a conservação moral; o mundo cívico mobiliza noções de equidade, liberdade e solidariedade; e o mundo mercantil é regido pelas leis de mercado, concorrência, lucro, individualismo.

Conforme o autor, as concepções de mundo inspiram concepções de justiça, de grandeza, de valores, de expressões de julgamento; há, no entanto, lugar para o encontro simultâneo de várias destas concepções. Os argumentos utilizados em uma disputa subsidiam princípios de ação que são diferentes. Essa diferença é importante, mas ressalta-se o caráter de complementariedade existente entre as diversas concepções, pois "a justiça é antes uma questão de interpretação cultural do que de argumentação filosófica” (KYMLICKA, 2006, p. 10), aspecto que ajuda a respaldar um critério universal que permita construir uma racionalidade prática a partir de um ponto de vista válido para cada coletivo singular.

É assim que se refere também à noção de justiça, que pode ser tratada como dilema, ou abertura para a escolha de uma opção teórica e conceitual, desde que esclarecida em seus princípios e que, neste entendimento, fomenta relações saudáveis, respeitosas, solidárias. Essa ideia não é tão inocente e singela como a abordagem da escola enquanto ambiente pacífico, "um lugar de consensos, avessa aos conflitos e responsável pela produção de relações harmônicas” (SCHILLING; ANGELUCCI, 2016, p. 697), nem tão estritamente vista como campo de batalha. Reforça-se aqui a compreensão de que a natureza das relações sociais se pauta em consensos e dissensos, engendrando impasses, bem como que a focalização sistemática da crítica potencializa o esclarecimento de pontos de vistas dissonantes, possibilitando a construção coletiva de entendimentos. 0 contrário, o silenciamento da crítica, por sua vez, fomenta conflitos, violências e injustiças.

A crítica ao simplismo encontra respaldo também em Rancière (2014, p. 81, grifo nosso), para quem é necessário "compreender as relações complexas entre democracia, política, república e representação, para compreender o ódio de hoje e encontrar a força subversiva da ideia democrática". 0 autor nos auxilia a perceber como as irrupções violentas no ambiente escolar manifestam certa crise da "revolução individualista rompendo o corpo social" (p. 26), assim como certo limite da escola no uso do diálogo como instrumento potencializador da argumentação e valoração coletiva.

0 debate conceitual apresentado auxilia a analisar as diversas maneiras como os escolares compreendem a justiça, verbalizada recorrentemente por meio de exemplos de injustiças vividas na organização escolar, reverberando antagonismos próprios da democracia, conforme o que se segue.

\section{Instigando o debate}

0 estudo de caso foi realizado numa escola de ensino médio da rede pública de Recife, em que foram recolhidos dados por meio da técnica do grupo focal. Essa técnica produz informações pela dinâmica interacional de um coletivo e torna-se importante especialmente em ambientes nos quais as relações de poder são caracterizadas por suas 
diferenças, como é o caso das escolas, não apenas no que se refere à distinção entre professores e alunos, mas também entre alunos, o que vem causando desconforto geral e afastamento. Conforme Gatti (2005, p. 11),

\begin{abstract}
0 trabalho com grupos focais permite compreender processos de construção da realidade por determinados grupos sociais, compreender práticas cotidianas, ações e reações a fatos e eventos, comportamentos e atitudes, constituindo-se uma técnica importante para o conhecimento das representações, percepções, crenças, hábitos, valores, restrições, preconceitos, linguagens e simbologias prevalentes no trato de uma dada questão por pessoas que partilham alguns traços em comum, relevantes para o estudo do problema visado.
\end{abstract}

0 grupo focal possibilita, portanto, melhor entrelaçamento dos dados, já que o debate faz aflorar certo jogo de influências que seria imperceptível em entrevistas ou questionários individuais. Facilita, portanto, a análise micropolítica e microssocial, tal como se propõe aqui, de examinar a expressão relativa às injustiças vividas por estudantes no cotidiano da escola democrática e as demandas decorrentes na organização escolar. Em outros termos, tais manifestações refletem as próprias experiências escolares de conflitos, violências e de injustiças vividas e reverberam como demandas, muitas vezes contraditórias, por direitos. As relações face a face permitem observar como a ordem social é permanentemente reconstruída pela negociação entre os indivíduos.

A escolha da escola seguiu critério anteriormente estipulado, sendo eleita uma entre duas escolas observadas na primeira etapa da pesquisa ${ }^{3}$, localizada em uma região de periferia em Recife, com vistas ao aprofundamento da análise.

Foram convidados estudantes, durante o recreio escolar, que voluntariamente se dispuseram a participar do estudo, já cientes do tema a ser tratado. Consolidaram-se dois grupos focais cujas discussões foram registradas com gravação de áudio: o Grupo 1 teve a participação de oito estudantes do terceiro ano do ensino médio (seis meninas e dois meninos) e o Grupo 2 contou com seis estudantes do primeiro ano (duas meninas e quatro meninos). Para cada grupo, exibiu-se inicialmente um extrato do filme Entre os muros da escola (2008), que aborda conflitos e relações interpessoais numa escola francesa, com o objetivo de estimular o debate com apoio de um roteiro semiestruturado de perguntas, cujos eixos geradores foram violência, indisciplina e injustiça na escola. Esclarece-se que, em etapa anterior da pesquisa ${ }^{4}$, foram tratadas as concepções dos estudantes a respeito do conceito de justiça que, por esse motivo, não será discutido aqui.

As entrevistas gravadas em áudio foram transcritas posteriormente. Os dados foram tratados, numa pré-análise, por meio da categorização pelos mesmos temas, sendo, em seguida, analisados de acordo com as subcategorias que emergiram dos debates: religião,

3- A pesquisa global trabalhou com quatro escolas de ensino médio, uma de região central e outra de periferia urbana, em Recife, no Brasil, e Braga, em Portugal. A escola selecionada para esta última etapa seguiu os critérios de localização em periferia urbana de Recife, de aproximação geográfica com a instituição de ensino superior de vínculo, de modo a facilitar 0 acesso nos momentos de coleta de dados, além de haver estudantes que se disponibilizaram a participar espontaneamente e forneceram autorização dos responsáveis.

4- Cf. Botler (2018). 
escola pública/particular e racismo, conforme abordagem da Análise de Conteúdo (BARDIN, 1977).

Com vistas a preservar suas identidades, optou-se por nominar os alunos com numeração simples, seguida do gênero. 0 resultado encontra-se sintetizado na Tabela 1:

Tabela 1 - Sujeitos da pesquisa - grupo focal

\begin{tabular}{ccccc}
\hline SUJEITOS & Masculino & $\vdots$ & Feminino \\
\hline Grupo 1 (30 ano) & $\vdots$ & 12M, 13M & $\vdots$ & 7F, 8F, 9F, 10F, 11F, 14F \\
\hline Grupo 2 (10 ano) & $\vdots$ & 2M, 4M, 5M, 6M & $\vdots$ & 1F, 3F \\
\hline
\end{tabular}

Fonte: Dados da pesquisa.

Dois dos catorze estudantes envolvidos pouco opinaram ou não tiveram suas expressões selecionadas para efeito deste artigo. 0 estudante 6M é surdo e contou com o auxílio de intérprete durante a sessão nos momentos em que contribuiu com suas ideias e críticas, e 12M é cego, tendo contado com a ajuda de uma das alunas do grupo para realizar a leitura do vídeo que foi exibido no início do encontro. Nos extratos de diálogos, identificaram-se as pesquisadoras-moderadoras dos debates com a letra P.

Estes procedimentos permitiram estimular o debate a respeito dos temas assinalados, permitindo vocalizar os dilemas presentes no ambiente escolar, bem como potencializando a elaboração de sentidos por parte dos sujeitos diante dos conflitos antes imperceptíveis. Tal perspectiva coaduna com o que sugerem Ball, Maguire e Braun (2016), quando tratam da atuação de sujeitos num complexo contexto particular, com foco nas práticas escolares, ou melhor, na micropolítica.

\section{Quando as injustiças vividas ajudam a elucidar as diferenças}

Dos debates nos grupos focais, emergiram manifestações dos estudantes a respeito das relações interpessoais ali travadas e de princípios e valores circulantes naquele ambiente, incluindo diversas expressões de preconceito relativas à raça, credo e posição socioeconômica. Revelaram a demanda por espaços de diálogo, bem como conceitos que carecem e merecem ser trabalhados na escola.

Chamou particular atenção o fato de cinco dos catorze estudantes afirmarem serem provenientes de escolas privadas sem que fossem perguntados sobre isso. Ao responderem a questões relativas a conflitos e violências percebidas ou sofridas, relataram suas experiências em outras escolas pelas quais passaram e compararam com a atual, campo da pesquisa, tendo apresentado os motivos de sua saída da escola anterior, a exemplo do extrato que se segue:

1F: Eu sempre estudei em colégio particular, colégio grande. E não era muito agradável porque eu sofria racismo dos próprios professores lá dentro. Não era racismo de eles chegarem e me falarem isso, mas coisas do tipo, eu fazer uma pergunta ao professor e ele nem olhar pra mim, nem falar 
comigo. [...] E não é só o professor que faz isso, não; é aluno na própria sala também! Porque já chegaram a tirar [onda, brincadeira], fazer bullying comigo, a fazer um monte de coisas comigo dentro da sala de aula!

A aluna negra trata do preconceito sofrido na escola privada em que estudou anteriormente como um dos motivos de sua mudança para a pública. Mas se sabe que as avaliações em larga escala consideram, entre suas alusões, a política de cotas para o ingresso de estudantes oriundos de escolas públicas no ensino superior, por exemplo, o que também teria levado algumas famílias a transferirem seus filhos da escola privada para a pública (BOTLER; SILVA, 2019). 0 relato aponta para o preconceito racial não apenas como motivo de migração, mas como tema que emergiu em meio ao grupo focal associado aos temas violências e injustiças. Destaca-se, na sequência do debate, que a mesma estudante que afirma ter sofrido injustiça na perspectiva do preconceito racial na escola privada, leva consigo certo preconceito em relação à escola pública:

1F: Eu tinha preconceito com pessoas que estudavam em colégio público, eu tinha.

3F: Eu também tinha.

1F: Eu, quando cheguei aqui, eu falei pra minha mãe "mãe, me leva embora, esse povo vai bater em mim!"

A estudante 1F refere-se ao momento em que ela se deparou com a realidade do convívio com colegas na escola pública, experiência que demandou o exercício da reflexão sobre pertencimento, fazendo os colegas pensarem nos processos identitários, na construção de caráter e, de certa maneira, na estereotipação de grupos ou de classes e no seu inverso, a incorporação no campo do pertencimento, a união. Tal reflexão emerge em meio aos diversos contextos em que se cerca, bem como denota as diversas maneiras de um mesmo sujeito se autocompreender e incorporar valores. Ainda no mesmo grupo do primeiro ano:

4M: Parece que quando a gente passa, é tipo, um exemplo, passa uma pessoa do M [escola particular] e passa uma pessoa da OV [escola pública, campo da presente pesquisa], eles nem percebem, mas, se ver, ficam falando alguma coisa e tal. [...] Eu digo, porque o que mais aconteceu - ela está de prova - eu não sabia que ela estava estudando aqui, porque eu já estudei com ela no S [escola particular], aí eu postei [nas redes sociais] uma foto minha com a camisa do governo [escola pública] e aí todo mundo colocou: "Eita, bebê do governo! Governante!" Os meninos lá do outro colégio [postaram]: "Governante! Governador!"

3F: Eu vi comentário na foto dele, muita coisa, assim, que pode parecer brincadeira pra eles, mas pra gente, na realidade, ninguém aqui ia gostar.

1F: Eles acham que estão na ostentação pelo fato de os pais deles estarem pagando escola. E sabem que o mais errado é que os pais deles estão pagando escola e eles não estão fazendo por merecer o que os pais deles pagam. Porque todos os meus amigos [na escola privada], nenhum estudava. Só eu, e eles filavam [copiavam] das minhas provas lá!

Segundo 4M, o simples fato de vestir o uniforme da escola pública já o estigmatiza, bem como provoca atitude preconceituosa dos alunos da escola particular, com os quais 
antes se identificava. 0 diálogo mostra que os estudantes oriundos de escolas privadas que afirmaram ter receio de sofrer retaliações na escola pública, sentiram que antigos colegas de escolas privadas passaram a tratá-los com desdém por estarem estudando em escola pública. Desta forma, os significados são socialmente atribuídos em cada contexto, corroborando a noção de justiça numa abordagem plural (WALZER, 2003).

Após o período de adaptação escolar, esses estudantes passaram a rever seus conceitos, desconstruíram impressões iniciais a respeito da escola pública e de seu público, chegando a externar a valorização do ensino agora vivenciado e demonstrando satisfação com o corpo docente e a afetividade com os colegas, revelando atualmente conhecer melhores experiências escolares.

Esse dado faz lembrar das afirmações de Dubet (2004) e Derouet (2010) já mencionados, focalizando o mérito da escola pública como um princípio, e a sensação de justiça ali experimentada em comparação com a injustiça vivida anteriormente.

10F: Eu fiquei com medo [no início] também, mas é o melhor ensino que eu já vi!

11F: 0 ensino é muito bom, o corpo docente da escola é muito bom.

0 dilema entre escola pública e escola particular enfatizado pelos alunos permite encontrar menções a certa adaptação social. Mas também revela o processo de identificação dos estudantes com a escola em que estudam, o que se entende como descobrimento de uma nova realidade, acesso a conhecimentos antes inexplorados. Esse envolvimento com a escola, após uma considerável quebra de paradigmas, é, para outros, um processo mais estendido. Tais conhecimentos e quebra de paradigmas deveriam ser problematizados sistematicamente na escola, gerando esclarecimento e ampliação do conhecimento, o que potencializa a justiça curricular (GOMES, 2019).

É o caso do aluno surdo (6M), que havia estudado até há pouco tempo em escola privada com atendimento exclusivo para surdos, passou por uma experiência em outra escola pública em que sofreu discriminação antes de mudar para a escola campo da pesquisa, e aponta diferenças no tratamento dos professores e entre os próprios alunos.

6M: Aconteceu, algum tempo atrás, umas pessoas ficaram de preconceito comigo, tiraram brincadeira comigo, um me derrubou, me escanteando mesmo! Assim... ele disse "ah, ele é muito feio!” Eu sou feio? 0 que importa minha aparência? Aí eu ficava calado, não revidava.

0 relato indica perplexidade e dor em relação ao comportamento dos colegas em experiências anteriores e segue lamentando as vivências escolares passadas, inclusive por outros colegas surdos:

6M: É muito diferente. Primeiro porque os professores [da escola privada] eram muito educados, com bom senso. Muitas vezes, aqui no governo, pelo que eu vejo, é um pouco diferente. Os alunos fazem muitas coisas erradas e eu não entendo, muitas vezes tem muitas brigas! Outro amigo que foi pra uma escola pública, que é a RL, lá acontecem muitas coisas que são muito difíceis. Realmente é muito ruim essa escola [RL]. Eu não quis ir pra lá, eu preferi estudar aqui. Eu conheci aqui e estou gostando aqui dessa escola. 
Observa-se que há distinção inclusive entre as duas escolas públicas em que ele e o colega surdo ingressaram, ou seja, não necessariamente entre as redes de ensino, o que denota a desconstrução de certo preconceito antes existente, o que se relaciona à elaboração efetivada em termos de conhecimento de outra realidade, ou atribuição de novos sentidos, como diz Fontes (2014). 0 problema está na discriminação sofrida e o sentimento de indignação decorrente.

As diferenças entre grupos ou categorias particulares, como é o caso do preconceito racial ou contra pessoas com deficiência, aparece ainda quando o assunto em tela é a religião. 0 tema surgiu no grupo do terceiro ano, quando se tratava das diferenças, levando à pergunta de se naquela escola havia pessoas identificadas com diferentes credos e como os professores deveriam agir diante de tais diferenças. Alguns alunos provenientes de escolas privadas confessionais se definiram com tal ou qual credo:

11F: Ela mesma, que é evangélica, têm várias escolas que são rigorosas e que não aceitam [outra religião]. E que realmente faz parte do padrão da escola. Aí a religião vai ter que aceitar, não só a escola vai aceitar a religião!

P: Era escola pública?

8F: Não, é particular.

P: 0 que vocês acham disso? [apontando para uma imagem de Jesus crucificado na parede da escola] 8F: Acho normal.

P: Não é injusto com quem não faz parte da crença cristã?

8F: Não!

11F: Da mesma forma que a gente tem que respeitar a religião deles, eles também têm que respeitar nossa religião. Se a gente acredita em deus, a gente entende eles não acreditarem.

8F: Não que eles estejam influenciando, porque depende da mente da pessoa. Mas... provavelmente esteja errado sim!

12M: Se a escola é pra ser laica, não deveria ter nenhum símbolo!

8F: Porque também não têm só católico, né? Aí pode ser que alguns cristãos, ateus se sintam ofendidos.

0 diálogo permite observar certa naturalidade com que os estudantes tratam da presença de imagens, símbolos e rituais no ambiente escolar, o que parece não ser tratado pedagogicamente no cotidiano. Destaca-se a expressão “tem que respeitar a religião deles”, indicativa de credo referente aos outros em oposição ao nós, demarcando certa distinção entre a religião assumida pela escola, por meio daquela imagem na parede, e a dos demais. A ausência da laicidade na escola pública é introjetada de forma irrefletida até que alguém levante a questão, tal qual ocorreu com 8F, que termina por reconhecer o equívoco do fato em si. Essa estudante aceita o argumento da colega por sua força e competência cognoscitiva, propiciada pelo diálogo. É pela ausência de tal problematização como regra geral que irrompem conflitos e proliferam injustiças, ou desordens sociais (DUBET, 2011), no caso em questão, por motivo de estudantes guardarem diferentes credos.

0 extrato anterior denota ainda que o tema não é objeto de discussão naquela escola, haja vista a parca bagagem argumentativa manifestada por estudantes na faixa 
etária dos 17/18 anos de idade, que já poderiam ter um pouco mais de discernimento. A questão pode ser tratada ainda a partir do aspecto cultural, que homogeneíza e normaliza o cristianismo como um dado naturalmente constituído, o que leva a não estranheza em relação aos objetivos, símbolos e signos cristãos, com base na máxima "Deus acima de todos”. 0 que chama a atenção, conforme as expressões dos estudantes, é o fato de a escola não problematizar um tema tão efervescente, que poderia ser gerador de sensibilização e identificação dos estudantes com a escola.

Este último diálogo, bem como os demais extratos já apresentados, permite perceber a reflexão promovida por meio do debate com colegas, possibilitando emergir a diversidade de identidades presentes naquele ambiente, bem como o processo de amadurecimento e transformação identitária ali propiciado. Além disso, fica evidente o modo como as relações interpessoais se desenvolvem com suporte da crítica estabelecida naquele grupo específico, corroborando as expressões de Louro (2010), Hall (2006), Berger e Luckmann (1985), apresentadas anteriormente neste artigo.

Com o grupo do primeiro ano, o assunto surgiu atrelado à ideia de intolerância religiosa, quando questionaram a atitude de uma colega perante alunos que demonstraram não ter fé cristã ou que não se identificam por meio de alguma crença religiosa:

1F: É que têm pessoas lá na sala que, se você falar qualquer coisa sobre deus... [arregala os olhos] 3F: Só E [aluna], só ela!

1F: Eu respeito, você é ateu, você tem a sua convicção. Então não precisa engolir a pessoa porque ela não acredita naquilo, é a opinião dela!

3F: E ela sai gritando se você falar qualquer coisa [diferente]!

4M: Na aula de física a gente debateu muito sobre religião.

3F: Que nem L [aluno] falou, que ele achava errado debater sobre religião, eu já não acho. Eu acho errado as pessoas não terem mente aberta pra aceitar a opinião de cada um. Porque religião não é uma coisa que vai ter só uma resposta. Cada um tem sua opinião, cada um tem suas crenças e só cabe a você ter mente aberta pra aceitar todas elas e tentar entender, "pô, que massa o seu lado!".

Nota-se como emergem valores no debate entre os estudantes, como respeito para com o outro e pluralidade de ideias, reforçando a concepção do jovem como relação social favorecendo sua natureza enquanto ator plural (DAYRELL, 2003). 0 extrato permite deduzir que há, por parte de alguns, certa clareza quanto às diversas concepções de mundo que inspiram diferentes valores, ou ainda, certa noção de justiça plural, como aponta Walzer (2003), pautada na comunidade de referência. Na sequência da discussão, novos elementos aparecem:

4M: Minha madrinha é espírita e eu estava começando a ir pro centro espírita com ela, e eu gostei muito. E eu fui falar pros meus amigos, né? Porque eu conto tudo pra eles! E eles ficaram rindo de mim, dizendo que era macumba! Tipo zoando mesmo, rindo e dizendo que fazer isso era macumba! 
1F: É muita intolerância! Mas isso vem da educação de cada um também, eles foram educados pra saber que aquilo ali é o certo, e tudo que não for igual aquilo é errado. A gente tem que mudar, tem que ter alguma disciplina, tem que inventar alguma disciplina pra isso também.

Coelho e Coelho (2015), como já foi citado, auxiliam a esclarecer que fazem parte do universo vivido na escola, tanto o sentimento de discriminação quanto a crítica à intolerância e a consequente demanda por ação propriamente pedagógica. Essas expressões denotam distintos princípios de ação que subsidiam suas noções de injustiças.

0 conteúdo da conversa reforça seu poder gerador da realidade e a sua ausência parece ser compensada por sua intensidade, como se observa no extrato, mas também incorre no risco de extremismos, que frequentemente desencadeiam ações violentas. Conforme Berger e Luckmann (1985, p. 205, grifo nosso),

A "autoridade" consiste na condição cognoscitiva e normativamente superior que é atribuída a determinadas conversas. A realidade subjetiva depende sempre de estruturas especificas de plausibilidade, isto é, da base social específica e dos processos sociais exigidos para sua conservação.

Assim, o indivíduo só preserva suas crenças, bem como a autoidentificação como um valor, em um meio que favorece esta identidade. $\mathrm{Ou}$, acrescenta-se, modifica suas posições e valores na medida em que afloram argumentos substantivos em debates entre colegas, como os promovidos nos grupos focais realizados, tal como esclarecem Schilling e Miyashiro (2008, p. 253):

A coexistência pacifica de formas distintas de vida deveria se tornar possivel. A ideia de polissemia e de diferentes possibilidades de viver, na pós-modernidade, refere-se em geral, primeiro e acima de tudo, a uma aceitação da pluralidade do mundo.

As autoras, bem como Berger e Luckmann (1985), esclarecem que o processo de socialização implica na possibilidade de transformação, inclusive da realidade subjetiva, dentro de um contínuo processo histórico. Desta forma, oprime, especialmente quando não se encontram forças em argumentos consistentes. A ausência de argumentação é observada na expressão de preconceito vivido por uma estudante que manifesta o sentimento de injustiça sofrida na escola frequentada anteriormente:

3F: Então, isso do racismo, eu sofri lá no $\mathrm{S}$ [colégio particular], eu estudava lá. Só que eu era muito pequena. E eram certas coisas, chegou um tempo do colégio que eu só via, só tinha eu e meu irmão de negros e mais um casal de alunos negros também. Mas já eram do ensino médio. E eu me senti... nossa, eu sou o pontinho preto! E tipo, eu já me sentia diferente por isso, mas eu não era muito de ligar pra isso, então, tinha algumas coisas de professores, de umas duas professoras minhas, que elas me tratavam um pouco, assim, diferente, eu não sei explicar. Mas sabe quando você sente que é aquilo, mas não têm como explicar pra outra pessoa pra ela entender? Mas a gente sabe... 
Injustiças vividas e demandas por reconhecimento numa escola pública: expressões de estudantes de ensino...

Certa experiência vivida por outro aluno vai na mesma direção:

4M: Uma vez, quando eu estudei em colégio particular, eu tinha muitos amigos na minha sala, eu também era muito participativo, quando era menor. Aí eu me candidatei para ser representante de sala, eu ganhei e tudo, só que eu não consegui botar nenhuma das minhas ideias em prática. Tipo, quando os alunos pediam pra eu fazer alguma coisa, eu ia na diretoria - porque tinha que ir diretamente na diretoria - falava com ela [diretora] e ela não me dava ouvido. Aí tinha uma menina lá [branca] que era minha amiga também, só que ela ia lá e a diretora fazia tudo pra ela. Tipo, ela pedia, ela [diretora] fazia tudo rapidinho. Eu sentia: pra quê fazer isso comigo? Eu não fui eleito, né? Só quem me ajudava eram as professoras mesmo, porque elas eram legais. Aí fui, acabei saindo do cargo. Deixei pra menina [branca]!

A estigmatização sofrida, manifestada inclusive por parte da gestora escolar, conforme declararam os estudantes, contribui para o empobrecimento dos laços sociais, afasta pessoas de práticas espontaneamente saudáveis e destrói projetos. Mas a escola poderia ser lugar de projeto de vida, de geração de expectativas de futuro, usina de pensamento crítico e prospectivo. Poderia vir a ser lugar de construção de um projeto civilizador de horizontalidade nas relações, de equidade.

A possibilidade do diálogo permite, como foi observado, extravasar sentimentos contidos, frutos de experiências vividas em seus distintos ambientes sociais. A sua simples exteriorização potencializa a ampliação do universo conceitual e a sensibilização quanto ao olhar do outro, o reconhecimento do outro, de cada sujeito envolvido no debate. Permite também à escola perceber tais expressões e utilizá-las para problematizar e resolver dilemas de seu cotidiano, fortalecendo a identificação dos estudantes.

\section{Conclusões}

0 artigo analisou a expressão relativa às injustiças vividas no cotidiano da escola democrática e às demandas decorrentes. Trata-se de um recorte de uma pesquisa mais ampla que analisou as concepções que estudantes têm de justiça e injustiça, o que se relaciona às situações de conflitos e violências vividos na organização escolar.

Os grupos focais possibilitaram a manifestação de algumas particularidades interessantes, que indicam a forte presença de discriminação religiosa e racial como elemento que aparta colegas ao invés de aproximá-los, poda iniciativas espontâneas de práticas sociais participativas, gera o sentimento de injustiça em parte dos escolares e os leva a apresentar resistências à escola. Tais percepções, ao serem confrontadas, permitem extravasar valores e princípios antes silenciados no cotidiano escolar, o que potencializa a emergência de demandas por direitos, dando voz a novos valores.

Ao estimular a discussão sobre conflitos e violências experimentados na escola, observou-se aflorar certo sentimento de injustiça, o que foi possível com apoio da técnica do grupo focal, que permitiu a aproximação com os estudantes, bem como oportunizou que eles entrassem em contato diretamente com as opiniões dos outros e suas discordâncias entre si. Os estudantes sentiram o valor de serem escutados e refletiram sobre seu lugar naquele coletivo, assim como mobilizaram o exercício da alteridade. 
Seu universo conceitual a respeito dos temas levantados é complexo e multifacetado, pautado nas relações interpessoais experimentadas e nas formas de tratamento das injustiças daí decorrentes. Dentre os impasses que emergiram, destaca-se a discriminação religiosa, bem como a diferenciação aludida pelos estudantes entre a escola pública e a privada, valorizando a primeira como lugar de aprendizagem e afetividade, e ressaltando a segunda como ambiente repleto de discriminação. Tais experiências configuram dilemas experimentados nos diversos ambientes em que vivem, repercutindo nos seus caminhos percorridos pelo campo das desigualdades sociais sob diversos prismas. Esses dilemas constituem sua referência em termos de sentimento de injustiça, por um lado, bem como de concepção de justiça, por outro, corroborando o que dizem Dubet (2004) e Derouet (2010).

Confere-se, portanto, à justiça a ideia de uma convivência isenta de qualquer forma de discriminação, que sonega, de alguma forma, a violência implícita, mas que é claramente acessível à ação educativa escolar democrática. As práticas escolares têm fundamental importância na minimização da discriminação e qualificação de sociabilidades, o que pode ser efetivado ao se considerar o universo instável em que os jovens vivem, as formas como as relações de desigualdade de classes sociais estão estabelecidas, o contexto histórico e social que leva estudantes a se sentirem como o "pontinho preto" relatado pela estudante 3F, o que também reforça a tese de Brubaker e Cooper (2018), que relacionam a objetificação enquanto processo social e prática intelectual.

As práticas de discriminação refletem na escola aquilo que a sociedade vive, mas, ressalta-se, nesse espaço encontram arena propícia à sua minimização a partir do debate substantivo, argumentado e democrático, que potencializa a formação cidadã e uma reconfiguração pedagógica que permite a afirmação das identidades, especialmente das minorias, como aprendizado axiológico mediado pelas manifestações da multiculturalidade subjacente à escola pública.

Nestes termos, conclui-se que na micropolítica escolar, tal como propõem Ball, Maguire e Braun (2016), configura-se uma democracia repleta de valores divergentes, em que estudantes têm suas identidades religiosas, étnicas e raciais afrontadas de forma nem sempre lúcida, gerando frequentemente violências entre pares e entre profissionais e estudantes. Mas, ao experimentarem a oportunidade do debate, verbalizam com clareza sua demanda por reconhecimento, por uma outra cidadania. 0 sentimento de injustiça vivida tanto os leva a apresentar resistências como potencializa sua identificação com o universo escolar específico.

A escola, por sua vez, na visão dos estudantes, falha ao evitar o debate a respeito de temas tão presentes ali e perde oportunidades de mobilizar estudantes na perspectiva de uma maior aproximação, o que a respaldaria a atuar de forma incisiva e pedagógica, permitindo aflorar dialogicamente as diferenças em busca da construção de sintonias e respeito mútuo, bem como a distanciaria das violências experimentadas. Nestes termos, as injustiças vividas e verbalizadas potencializariam o esclarecimento das diferenças como algo inerente às culturas, sem hierarquizá-las, assim como contribuiriam para a redução dos preconceitos democraticamente, abrindo espaço ao pluralismo e à alteridade, reivindicação mais do que urgente a ser enfrentada. 


\section{Referências}

BALL, Stephen; MAGUIRE, Meg; BRAUN, Annette. Como as escolas fazem políticas. Tradução Janete Brindon. Ponta Grossa: UEPG, 2016.

BARBOSA, Manuel Gonçalves; MÜHL, Eldon Henrique. Educação, empoderamento e lutas pelo reconhecimento: a questão dos direitos de cidadania. Educação e Pesquisa, São Paulo, v. 42, n. 3, p. $789-802,2016$

BARDIN, Laurence. Análise de conteúdo. Tradução Luís Antero Reto e Augusto Pinheiro. Lisboa: Ed. 70, 1977.

BERGER, Peter; LUCKMANN, Thomas. A construção social da realidade: tratado de sociologia do conhecimento. Petrópolis: Vozes, 1985.

BOTLER, Alice Miriam Happ. Justiça e democracia na escola: a arte de justificar práticas. ETD: Educação Temática Digital, Campinas, v. 20, n. 2, p. 305-324, 2018.

BOTLER, Alice Miriam Happ; SILVA, Viviane Alves de Lima. Desigualdade de oportunidades: "injustiças democráticas" em colégios de aplicação. Revista Profissão Docente, Uberaba, v. 19, n. 41, p. 1-17, 2019.

BRUBAKER, Rogers; COOPER, Frederick. Para além da "identidade". Antropolítica, Niterói, n. 45, p. 266-324, 2018.

COELHO, Wilma de Nazaré Baía; COELHO, Mauro Cezar. Preconceito e discriminação para além das salas de aula: sociabilidades e cultura juvenil no ambiente escolar. Revista do Instituto de Estudos Brasileiros, São Paulo, n. 62, p. 32-53, 2015.

DAYRELL, Juarez. 0 jovem como sujeito social. Revista Brasileira de Educação, Rio de Janeiro, n. 24, p. 40-52, 2003.

DEROUET, Jean-Louis. Crise do projeto de democratização da educação e da formação ou crise de um modelo de democratização? Algumas reflexões a partir do caso francês (1980-2010). Educação \& Sociedade, Campinas, v. 31, n. 112, p. 1001-1027, 2010.

DUBET, François. Injustiças: a experiência das desigualdades no trabalho. Florianópolis: UFSC, 2014.

DUBET, François. Mutações cruzadas: a cidadania e a escola. Revista Brasileira de Educação, Rio de Janeiro, v. 16, n. 47, p. 289-305, 2011.

DUBET, François. 0 que é uma escola justa? Cadernos de Pesquisa, São Paulo, v. 34, n. 123, p. 539-555, 2004.

ENTRE os muros da escola. Direção: Laurent Cantet. Paris: Haut et Court, 2008. 1 DVD (128 min).

ESTÊVÃO, Carlos Alberto Vilar. Educação, justiça e democracia. São Paulo: Cortez, 2004. 
FONTES, Breno. Tecendo redes, suportando o sofrimento: sobre os círculos sociais da loucura. Sociologias, Porto Alegre, v. 16, n. 37, p. 112-143, 2014. Disponível em: http://www.scielo.br/scielo.php?script=sci_ arttext\&pid=S1517-45222014000300112\&lng=pt\&nrm=iso. Acesso em: 11 jul. 2019.

GATTI, Bernardete Angelina. Grupo focal na pesquisa em ciências sociais e humanas. Brasília, DF: Liber Livro, 2005.

GOMES, Nilma Lino. Educação e relações raciais: refletindo sobre algumas estratégias de atuação. In: MUNANGA, Kabengele (org.). Superando o racismo na escola. 2. ed. Brasília, DF: MEC: Secretaria de Educação Continuada, Alfabetização e Diversidade, 2005. p. 143-154.

GOMES, Nilma Lino. Raça e educação infantil: à procura de justiça. Revista e-Curriculum, São Paulo, v. 17, n. 3, p. 1015-1044, 2019.

HABERMAS, Jürgen. Consciência moral e agir comunicativo. Rio de Janeiro: Tempo Brasileiro, 1989.

HALL, Stuart. A identidade cultural na pós-modernidade. 11. ed. Rio de Janeiro: DP\&A, 2006.

KYMLICKA, Will. Filosofia política contemporânea. São Paulo: Martins Fontes, 2006.

LOURO, Guacira Lopes. Gênero, sexualidade e educação: uma perspectiva pós-estruturalista. Petrópolis: Vozes, 2010.

RANCIĖRE, Jacques. 0 ódio à democracia. São Paulo: Boitempo, 2014.

SCHILLING, Flávia, ANGELUCCI, Carla Biancha. Conflitos, violências, injustiças na escola? Caminhos possiveis para uma escola justa. Cadernos de Pesquisa, São Paulo, v. 46, n. 161, p. 694-715, 2016.

SCHILLING, Flávia; MIYASHIRO, Sandra Galdino. Como incluir? 0 debate sobre o preconceito e o estigma na atualidade. Educação e Pesquisa, São Paulo, v. 34, n. 2, p. 243-254, 2008.

VEIGA, Cynthia Greive. Discriminação social e desigualdade escolar na história política da educação brasileira (1822-2016): alguns apontamentos. História da Educação, Porto Alegre, v. 21, n. 53, p. 158-181, 2017.

WALZER, Michael. Esferas da justiça: uma defesa do pluralismo e da igualdade. São Paulo: Martins Fontes, 2003.

Recebido em: 27.05.2020

Revisado em: 05.08.2020

Aprovado em: 14.09.2020 
Alice Miriam Happ Botler é docente do Centro de Educação da Universidade Federal de Pernambuco (UFPE), doutora em sociologia, fez pós-doutorado na University of Toronto e estágio sênior na Universidade de São Paulo (USP). É vice-coordenadora do Programa de Pós-graduação em Educação da UFPE, líder do Grupo de Pesquisa Estudo das Organizações Educativas e bolsista Pq2 CNPq. 